\title{
Assessing Secondary Trauma, Compassion Satisfaction, and Burnout - Implications for Professional Education for Asian-American Social Workers
}

\author{
Kenny Kwong ${ }^{1}$ \\ ${ }^{1}$ Graduate School of Social Work, Touro College, New York, New York, United States \\ Correspondence: Kenny Kwong, Graduate School of Social Work, Touro College, New York, New York, United \\ States. E-mail: kam.kwong@touro.edu
}

Received: September 7, 2018

Accepted: September 25, 2018

Online Published: September 26, 2018

doi:10.5430/ijhe.v7n5p75

URL: https://doi.org/10.5430/ijhe.v7n5p75

\begin{abstract}
The present study explored work-related stress and career experiences of Asian-American social workers and assessed if their demographic characteristics, beliefs and orientations (altruism, idealism, and self-compassion), and work-related stressors might impact their professional quality of life (secondary trauma, compassion satisfaction, and burnout) and job-related health problems. Two hundred and eight (208) Asian social workers and students participated in a comprehensive online survey by providing basic demographic and work-related information and completing a set of standardized scales to assess their career experiences and work-related stress, as well as their psychological and physical well-being. Bivariate analyses and stepwise multiple regression analyses were used to estimate models that best predicted their experiences of secondary trauma, compassion satisfaction, burnout, perceived stress, and job-related health problems. The findings showed that higher perceived stress was associated with higher secondary trauma, burnout, job-related health problems, and lower compassion satisfaction. Work-related problems/stressors emerged as a very strong predictor of burnout and job-related health problems. Higher self-compassion was related to higher compassion satisfaction and lower secondary trauma and burnout. Self-compassion was found to be a very strong predictor of perceived stress. Implications of the findings for professional education and career development for Asian-American social workers were discussed.
\end{abstract}

Keywords: Asian social workers, work stress, career experience, self-compassion, secondary trauma, burnout, compassion satisfaction

\section{Introduction}

According to the 2016 Statistics on Social Work Education in the United States (Council on Social Work Education, 2017), $1.9 \%$ of Bachelor's degree and 3\% of Master's degree in social work graduates in 2016 were Asian-Americans or other Asians, much lower than the percentage of Asian Americans (6.4\%) in the total U.S. population (US Census Bureau, 2015). The Asian population has the fastest growth rate among all the major racial or ethnic groups in the U.S. and between 2000 and 2015, it grew 72\% (Pew Research Center, 2017). There has been a tremendous gap in recruiting and retaining adequate number of Asian-American social work professionals to meet the needs of social services and health care of the rapidly rising Asian-American populations.

The practice of social work offers unique challenges that can be both satisfying and potentially stressful for them. Social workers are committed to serve vulnerable and disadvantaged populations. They often work with victims of family violence, childhood abuse and neglect, trauma, crime, and serious mental disturbance (Bride, 2007; Collins \& Long, 2003; Gately \& Stabb, 2005). Social workers providing direct services, particularly in highly emotionally taxing practice settings such as substance abuse, behavioral health, and emergency care, often face obstacles that may make them feel overwhelmed and stressed (Fahy, 2007; Naturale, 2007; Ting, Saunders, Jacobson, \& Power, 2006). Research on Asian American career experiences and work-related stress has been extremely limited. Very few studies have explored factors that may associate with career choices and career advancement among Asian-American social workers (Hwang, 2007; Lee, 2009). Greater understanding of the work-related stress and career experiences among Asian-American social work professionals is necessary to further our knowledge on the nature and extent of their work-related stress, career development, and psychological and physical well-beings. 


\section{Literature Review}

Social workers face numerous challenges when they work with highly complicated and high-risk clients such as those who attempt or commit suicide; clients with severe health or mental health problems and who do not improve; those who display high-risk behaviors; and those who perpetrate abusive or aggressive behaviors against others (Bongar \& Stolberg, 2009; Gately \& Stabb, 2005; Ting et al., 2006). They are often "pushed to the limit" and feel stressed when they try to complete their work with limited resources and under less-than optimal work environments. Work-related stress can result in interpersonal conflicts, decreased concentration, work-place injury, impaired cognitive functioning, poor health and mental health, and poor self-confidence/self-esteem (Arrington, 2008; Cox \& Steiner, 2013). It is important for social workers to be aware of the nature and sources of work-related stress, create therapeutic relationships with their clients without compromising their own psychological health, and establish professional boundaries with difficult clients (Kwong, 2016).

\subsection{Compassion Satisfaction, Secondary Traumatic Stress and Burnout among Social Workers}

Existing literature on work-related stress experiences and outcomes have focused on several major constructs including compassion satisfaction, compassion fatigue, secondary traumatic stress, and burnout (Figley, 2002; Newell \& MacNeil, 2010; Pryce, Stackelford, \& Pryce, 2007; Smullens, 2012, Stamm, 2002). Compassion satisfaction assesses the level of satisfaction and pleasure derived from providing care to clients (Stamm, 2002) and was found to be a protective factor for psychotherapists to cope with the stresses associated with counseling others. Compassion fatigue was defined as "a state of tension and preoccupation with the traumatized patients by re-experiencing traumatic events, avoidance/numbing of reminders; persistent arousal (e.g., anxiety) associated with the patient" (Figley, 2002, p.1435). Secondary Traumatic Stress was described as an occupational hazard of providing direct services to traumatized populations (Figley, 1999). Bride (2007) found that clinical social workers were at risk of secondarily exposed to traumatic stress through their direct practice with traumatized populations. Clinical work with victims of violence and other traumatic experiences may lead to secondary victimization of the therapist (Figley, 1999; Newell \& MacNeil, 2010; Weitkamp, Daniels, \& Klasen, 2014).

A review of related literature found that helping professionals were at risk for adverse psychological and physical consequences due to the emotional nature of the work (Coyle, Edwards, Hannigan, Fothergill, \& Burnard, 2005; Stamm, 2002; Ting et al., 2006). The very enthusiasm and idealism of the social worker that encourages altruistic values, and their prolonged exposure to traumatic stress, can result in personal exhaustion, overextension, impaired professional competence, and burnout (Barnett et al., 2007; Collins \& Long, 2003; Schaufeli, Leiter, \& Maslach, 2009). Compassion fatigue was found to associate with a sense of confusion, feeling helplessness, and social isolation among helping professionals (Figley, 2002) and psychological distress among social workers (Adams, Boscarino, and Figley, 2006). If left untreated, compassion fatigue may cause a range of physiological symptoms and psychological problems, as well as unhealthy behaviors or lifestyles (Figley, 2002). Burnout was described as "the terminal phase of therapist distress" (Baker, 2003). Because of excessive work, a lack of support in work environments, and constant exposure to emotionally challenging client situations, caring professionals often have the feelings of depersonalization, a lack of sense of accomplishment, and emotional exhaustion (Baker, 2003). In sum, social workers need to learn about their potential risk of exposure to traumatic stress, separate their personal life from work, enhance their ability and efficacy to manage work-related stress, access to more professional and social support, and regain a sense of competence and mastery over their work situations (Badger, Royse, \& Craig, 2008; Figley, 2002; Shoji, et al., 2014). More research and understanding on the nature and sources of traumatic stress, compassion fatigue, and burnout is very much needed to facilitate training and professional development for social workers to learn how to manage stress as well as to promote their own psychological wellness and self-care (Dziegielewski, Turnage, \& Roest-Marti, 2004; Kwong, 2016).

\subsection{Job-related Stress and Career Experiences among Asian-American Social Workers}

Existing research on Asian-American social worker career experiences and work-related stress remains very limited. There is a paucity of literature that explore various factors such as personal, cultural or other factors that may associate with specific career experiences and work-related stress among Asian-Americans social workers. Lee (2009) explored factors that influenced career choice of Asian-American social workers and found that family immigration status have significantly impacted the perception of career barriers and career choice of being a social worker. Hwang (2007) explored the phenomenon of glass ceiling and its effects on Asian-Americans' careers in social work. A review of related literature found a few studies of career experiences among minority social work students and practitioners. Daniel (2011) summarized several career related concerns among racial and ethnic minority social work students that included burnout, inability to effect change due to agency bureaucracy, and the 
negative and stereotypic perceptions of low income, minority clients. Minority students want to become social workers because of their desire in working with poor and vulnerable populations. Moriarty and Murray (2007) found low level of compensation and low occupational status as barriers for men to pursue social work as their career. Wilson and McCrystal, 2007) argue that unresolved trauma, work stress, and limited organizational support, may create barriers in social work field to enhance professional development and retention of minority social workers. In summary, there is need for more research on career experiences and work-related stress among Asian-American social workers.

\section{Methods}

The present exploratory study used an online survey design to address the following questions:

1. What were the career experiences of Asian-American social workers, i.e. experiences of work-related problems/stressors, secondary trauma, compassion satisfaction, burnout, and job-related health problems? Were there correlations between these variables?

2. What factors might contribute to secondary trauma, compassion satisfaction, and burnout?

3. What were the sources and predictors of work-related stress perceived by Asian-American social workers? How did they manage the stress?

4. Did personal characteristics, beliefs and idealism, and work-related stressors result in job-related health problems?

\subsection{Procedures}

This study used convenient and snowball sampling to recruit potential participants. It was a multistep process. First, the researcher compiled an extensive list of Asian-American organizations including local and national service networks, in New York/New Jersey, California, Hawaii, and Midwest regions, as well as social work schools and national social work educator association. The researcher then sent an email to these organizations to inform them about the purpose of the study and ask for their support to forward or post an invitation letter to all their members. To maximize the ethnic diversity of the sample, the researcher reached out to organizations serving predominately ethnicity subgroups including Chinese, Koreans, Japanese, Filipinos, and South Asians. In addition, an invitation letter was posted at various social media outlets of local and national chapters of social workers, and graduate social work students' associations. Finally, survey participants were asked to help invite their colleagues and friends to participate in the study.

The invitation email letter with the link to enter into the survey was sent to all potential participants to inform them about the purpose of the study, the anonymity of the survey, and that their participation in the survey was completely voluntary. Participants were told that it would take about 20 to 30 minutes to complete the survey. An online cross-sectional survey design was used to address the research questions. Participants were asked to provide basic demographic and work-related information and complete a set of standardized scales to assess their career experiences and work-related stress, as well as their psychological and physical well-being. These scales include: Social Work Idealism (Csikai \& Rozensky, 1997), Altruistic Reasons for Choosing Social Work as Career Scale (Csikai \& Rozensky, 1997), Self-Compassion Scale (Neff, 2003), Perceived Stress Scale (Cohen, Kamarck, and Mermelstein, 1983) and Professional Quality of Life Scale (Stamm, 2009-2012). When required, permission was obtained from the scale developers to use these scales for the study. Qualtrics Online Survey Software was used to create and administer the survey. The study was approved by Touro College's Institutional Review Board.

\subsection{Participants}

A total of 208 Asian-American or Asian social workers or graduate level social work students in the United States participated in this survey study. Their ages ranged from 21 to 68 years (mean =37). Eighty-two percent were females and $16.1 \%$ were male. The majority identified themselves as Chinese (51.2\%), followed by Korean (13.7\%), Japanese (8.9\%), Filipino (6.5\%), Asian Indians (4.2\%) and multi-racial (6.5\%). With regard to family immigration status, the majority $(83.2 \%)$ indicated that neither of their parents were born in the U.S. More than half $(53.6 \%)$ were not born in the U.S. The majority identified themselves as heterosexual (85.6\%) and married (52.7\%). Approximately $40 \%$ believed in Christianity, 9\% believed in Buddhism, and $45.6 \%$ had no religious affiliation. The majority worked full-time (75.3\%). About 41\% worked in social work-related profession for less than 4 years, $24.6 \%$ worked for 5-9 years, $16.8 \%$ worked for $10-19$ years, and $17.4 \%$ worked for 20 years or more. About $29 \%$ reported their annual income to be below $\$ 45,000,35 \%$ had annual income of $\$ 45,000$ to less than $\$ 75,000$. About $36 \%$ had annual income $\$ 75,000$ or more. Most of the participants lived in New York/New Jersey (49.7\%), California (17\%), Hawaii (13.7\%), Nevada (5.2\%), and Massachusetts (3.9\%). 
The majority (73.8\%) obtained a master's degree in social work, $13.1 \%$ had a bachelor's degree in social work or other related fields, and $8.3 \%$ had a postgraduate degree. Approximately $41 \%$ were direct practitioners/caseworkers, $9.1 \%$ were supervisors of direct practice, $10.8 \%$ were administrators, and $19.8 \%$ were graduate students. These participants worked in very diverse practice settings including mental health $(25.7 \%)$, health and disability services (18\%), education and schools $(10.8 \%)$, senior services $(10.8 \%)$, family or youth services $(6.6 \%)$, child welfare/child care $(5.4 \%)$, domestic violence $(2.4 \%)$, substance abuse $(1.8 \%)$ and housing $(3 \%)$. More than half of participants were supervised by social work professionals $(57.8 \%)$ and the rest of them were supervised by other disciplines including human service (15.1\%), education (7.8\%), business (4.2\%), and law (2.4\%).

\subsection{Measures}

\subsubsection{Demographics and Agency Characteristics}

The survey includes items that measure demographic characteristics such as age, gender, ethnicity, immigration status, parents' immigration status, sexual orientation, marital status, educational status, income level, work status, job title, job tenure, religion, and zip code. Agency characteristics variables include the supervisor's professional background and the primary focus of the program.

\subsubsection{Work-Related Problems/Stressors}

The National Association of Social Workers (NASW) Membership Workforce Study identified several job-related stressors commonly experienced by social workers (Arrington, 2008). This study adapted some of these stressors and added other relevant problems or stressors that were relevant for Asian-American social workers. Participants were asked to respond to a list of 18 work-related problems/stressors and indicated in a 4-point scale how frequent they experienced these problems ranging from "rarely/never" (1) to "very often" (4). Factor analysis was performed to identify factors underlying this list of variables. By clustering many variables into a smaller number of subsets, these variables can be reduced to a smaller, more manageable, and interpretable number of factors. These 18 variables were analyzed for reliability following which three items were removed. Four factors were identified: (1) workload and time/life commitment; (2) work nature, job quality, and support; (3) compensation and promotion; and (4) client and staff challenges. The revised 15 items had a Cronbach's alpha of .90 .

\subsubsection{Social Work Idealism}

The 26-item scale was designed to measure social work idealism (Csikai \& Rozensky, 1997). The scale was analyzed for internal consistency and three items were removed. The revised 23 items had a Cronbach's alpha of.74. The mean score for social work idealism among all respondents was $3.66(\mathrm{SD}=.27)$.

\subsubsection{Altruistic Reasons of Choosing Social Work as Career}

The Altruistic Reasons of Choosing Social Work as Career, a four-item scale, was administered to measure participants' motives for selecting a career in social work (Csikai \& Rozensky, 1997). The sample of this study yielded a Cronbach's alpha of.79.

\subsubsection{Self-Compassion}

Self-Compassion Scale was used to explore the thoughts, emotions, and behaviors associated with the various components of self-compassion (Neff, 2003). The scale comprised of 26 items and has 6 subscales - Self Kindness $(\alpha=.78)$, Self-Judgment $(\alpha=.77)$, Common Humanity $(\alpha=.80)$, Isolation $(\alpha=.79)$, Mindfulness $(\alpha=.75)$, and Over-Identified $(\alpha=.81)$. Neff (2003) reported the Cronbach's alpha for the Self-Compassion Scale as .92. The sample of this study yielded a Cronbach's alpha for the Self-Compassion Scale as .94. The Cronbach's alphas for the subscales were .86 (Self Kindness), .86 (Self-Judgment), .81 (Common Humanity), .80 (Isolation), .81 (Mindfulness), and .80 (Over-Identified).

\subsubsection{Perceived Stress Scale}

The Perceived Stress Scale, comprised of ten items, is a widely used psychological instrument to assess the perception of stress (Cohen et al., 1983). It is a measure of the degree to which situations in one's life are appraised as stressful. In this study, the scale was administered with the participants to assess how different situations affected their feelings and their perceived stress. The sample of this study yielded a Cronbach's alpha for the Perceived Stress Scale as .90 .

\subsubsection{Professional Quality of Life}

The Professional Quality of Life Scale, comprised of 30 items, has three distinct 10-item scales measuring compassion satisfaction, burnout, and secondary trauma (Stamm, 2009-2012). The Compassion Satisfaction Scale 
was administered to assess the pleasure and positive feelings derived from doing helping work. The Burnout Scale was used to explore feelings of hopelessness and difficulties in dealing with work or doing one's job effectively. The Secondary Traumatic Stress Scale was administered to assess the degree of secondary exposure to extremely or traumatically stressful events. Stamm (2009-2012) reported the Cronbach's alpha for Compassion Satisfaction Scale as .88, Burnout Scale .75 , and Secondary Traumatic Stress Scale .81. Reliability analyses indicated the internal consistency of the Compassion Satisfaction Scale as .88 for the current sample, Burnout Scale .75, and Secondary Traumatic Stress .83.

\subsubsection{Job-Related Health Problems}

Participants were asked to respond to a list of 14 job-related health problems and indicated in a 4-point scale how often they experienced these problems ranging from "rarely/never" (1) to "very often" (4). Factor analysis was performed to identify factors underlying this list of variables. By clustering a large number of variables into a smaller subsets, these variables can be reduced to a smaller, more manageable, and interpretable number of factors. These 14 variables were analyzed for reliability following which 4 items were removed. Two factors were identified. The Psychological Factor includes 6 items - feeling nervous, fidgety, tense, or anxious, feeling irritable and aggressive, trouble sleeping, trouble concentrating, feelings of powerlessness, and depression. The Physical/Somatic Factor includes 4 items - fatigue/lack of energy, neck and back pains, stomach/digestive problems, and impaired immune functions. The scale of revised 10 items had a Cronbach's alpha of 89 .

\subsubsection{Stress Management}

The NASW Membership Workforce Study identified a number of strategies social workers used to manage their stress (Arrington, 2008). This study adapted some of these strategies and added several more methods that may be used by Asian-American social workers. Participants were provided with a list of 9 strategies including drinking alcohol, cigarette smoking, use absenteeism, physical activity, body, mind, and spirit approach, professional therapy or counseling, gain support through a professional and social network, use of prescription medication, and stress management. They were asked to indicate if they have used any of them to manage work-related stress and regain a sense of control over their situation.

\subsection{Data Analytical Steps}

The Statistical Package for the Social Sciences (SPSS, version 23) was used to complete data analysis. Descriptive statistics (i.e. frequency distributions for all categorical variables and means and standard deviations for interval or ratio level variables), factor analyses (to identify a smaller subset of variables for two particular measures Work-related Problems/Stressors and Job-related Health Problems), reliability statistics (to assess the internal consistency of each scale), correlation analysis (to measure the linear association between variables), and regression analysis (to identify predictors of major outcome variables) were computed.

\section{Results}

\subsection{Descriptive Statistics and Correlations}

The descriptive statistics (means and standard deviations), scale reliability, and correlations between altruism, social work idealism, self-compassion, perceived stress, compassion satisfaction, secondary trauma, burnout, and job-related health problems, were displayed in Table 1.

Table 1. Means, Standard Deviations, Reliabilities, and Correlations among Study Variables

\begin{tabular}{llllllllllll}
\hline Variable & Mean & SD & $\alpha$ & 1 & 2 & 3 & 4 & 5 & 6 & 7 & 8 \\
\hline 1. Altruism & 24.69 & 3.70 & .79 & 1.0 & & & & & & & \\
2. Social work idealism & 91.79 & 6.96 & .74 & $.39^{* *}$ & 1.0 & & & & & & \\
3. Self-compassion & 87.38 & 18.6 & .94 & .02 & .13 & 1.0 & & & & & \\
4. Perceived stress & 17.5 & 6.69 & .90 & .07 & -.06 & $-.65^{* *}$ & 1.0 & & & & \\
5. Compassion satisfaction & 39.29 & 5.77 & .88 & $.48^{* *}$ & $.37^{* *}$ & $.35^{* *}$ & $-.27^{* *}$ & 1.0 & & & \\
6. Secondary trauma & 21.97 & 6.21 & .81 & $.23^{* *}$ & $.15^{*}$ & $-.41^{* *}$ & $.43^{* *}$ & -.04 & 1.0. & & \\
7. Burnout & 22.66 & 5.38 & .75 & -.12 & $-.16^{*}$ & $-.51^{* *}$ & $.55^{* *}$ & $-.58^{* *}$ & $.53^{* *}$ & 1.0 & \\
8. Job-related health problems & 18.94 & 6.54 & .89 & $.20^{*}$ & -.003 & $-.40^{* *}$ & $.56^{* *}$ & $-.20^{*}$ & $.55^{* *}$ & $.55^{* *}$ & 1.0 \\
\hline
\end{tabular}

**. Correlation is significant at the 0.01 level (2-tailed).

*. Correlation is significant at the 0.05 level (2-tailed). 
Among three subscales of Professional Quality of Life, burnout was correlated negatively with compassion satisfaction $(\mathrm{r}=-.58, p<.01)$ but positively with secondary trauma $(\mathrm{r}=.53, p<.01)$. There was no relationship between compassion satisfaction and secondary trauma. In this study, self-compassion was found to significantly influence the professional quality of life among these participants. The results showed that self-compassion was related positively with compassion satisfaction $(\mathrm{r}=35, p<.01)$ but negatively with secondary trauma $(\mathrm{r}=-.41, p<.01)$, burnout $(\mathrm{r}=-.51$, $p<.01)$, perceived stress $(\mathrm{r}=-.65, p<.01)$, and job-related health problems $(\mathrm{r}=-.40, p<.01)$. Meanwhile perceived stress was found to correlate negatively with compassion satisfaction $(\mathrm{r}=-.27, p<.01)$ but positively with secondary trauma $(\mathrm{r}$ $=.43, p<.01)$, and burnout $(\mathrm{r}=.58, p<.01)$. Finally, job-related health problems was found to relate negatively with self-compassion $(\mathrm{r}=-.40, p<.01)$ and compassion satisfaction $(\mathrm{r}=-.20, p<.05)$ but positively with perceived stress $(\mathrm{r}$ $=.56, p<.01)$, secondary trauma $(\mathrm{r}=.55, p<.01)$, and burnout $(\mathrm{r}=.55, p<.01)$.

\subsection{Factors Influencing Secondary Trauma, Compassion Satisfaction and Burnout}

The results showed the overall level of compassion satisfaction as average in this sample (mean $=39.29$ at a higher end of the average score between 23 and 41). The average score of burnout was 22.66 indicating low to average level of burnout. The mean score of secondary trauma was 21.97 indicating low to average range. Several stepwise multiple regression analyses were conducted to estimate models that would best predict the experience of secondary trauma, compassion satisfaction, and burnout among Asian-American social workers. Eight possible factors including age, gender, income, job tenure, work-related problems/stressors, self-compassion, altruism, and social work idealism were entered in regression analyses. The results revealed three factors as significant predictors of secondary trauma $(F=21.85 ; p<.05)$ (Table 2$)$. With a beta of.-.46 ( $p<.05)$, self-compassion emerged as the strongest predictor, accounting for $22.8 \%$ of the variance in secondary trauma. The second strongest factor was work-related problems/stressors $(\beta=.25 ; \mathrm{p}<.05)$ followed by social work idealism $(\beta=.23 ; \mathrm{p}<.05)$ accounting for $5.6 \%$ and $5.1 \%$ of the variance in secondary trauma. These results indicated that higher level of secondary trauma was a function of lower level of self-compassion, higher level of work-related problems/stressors and higher level of social work idealism. Overall, the model explained almost $34 \%$ of the variance in secondary trauma $(R=.58)$.

Table 2. Results of Multiple Regression Analysis - Predictors of Secondary Trauma

\begin{tabular}{llllllll}
\hline Factor & $R$ & $R^{2}$ & $\beta$ & $t$ & $p$ & $F$ & $P$ \\
\hline Self-compassion & .48 & .23 & -.46 & -6.12 & .000 & 38.98 & .000 \\
Work-related problems/stressors & .53 & .28 & .25 & 3.42 & .001 & 25.97 & .000 \\
Social work idealism & .58 & .34 & .23 & 3.16 & .002 & 21.85 & .000
\end{tabular}

With regard to compassion satisfaction, the results revealed five factors as significant predictors $(F=22.69 ; p<.05)$. With a beta of .41 ( $p<.05)$, altruism emerged as the strongest predictor, accounting for $23 \%$ of the variance in compassion satisfaction (Table 3$)$. The second strongest factor was age $(\beta=.26 ; p<.05)$ followed by self-compassion $(\beta=.19 ; \mathrm{p}<.05)$, work-related problems/stressors $(\beta=-.16 ; \mathrm{p}<.05)$, and social work idealism $((\beta=.17 ; \mathrm{p}<.05)$, accounting for $12.8 \%, 5.7 \%, 2.9 \%$, and $2.3 \%$ of the variance in compassion satisfaction. These results indicated that higher level of compassion satisfaction was a function of higher level of self-compassion, being older, higher level of self-compassion, lower level of work-related problems/stressors, and higher level of social work idealism. Overall, the model explained almost $47 \%$ of the variance in compassion satisfaction $(R=.68)$.

Table 3. Results of Multiple Regression Analysis - Predictors of Compassion Satisfaction

\begin{tabular}{llllllll}
\hline Factor & $R$ & $R^{2}$ & $\beta$ & $t$ & $p$ & $F$ & $P$ \\
\hline Altruism & .48 & .23 & .41 & 5.90 & .000 & 39.70 & .000 \\
Age & .60 & .36 & .26 & 3.70 & .000 & 36.76 & .000 \\
Self-compassion & .64 & .42 & .19 & 2.56 & .012 & 31.00 & .000 \\
Work-related problems/stressors & .67 & .44 & -.16 & -2.43 & .017 & 26.00 & .000 \\
Social work idealism & .68 & .47 & .17 & 2.38 & .019 & 22.69 & .000
\end{tabular}

With regard to burnout, the results revealed four factors as significant predictors $(F=41.82 ; p<.05)$. With a beta of .50 $(p<.05)$, work-related problems/stressors emerged as the strongest predictor, accounting for $32.6 \%$ of the variance in burnout (Table 4$)$. The second strongest factor was self-compassion $(\beta=-.35 ; \mathrm{p}<.05)$ followed by age $(\beta=-.19 ; \mathrm{p}<.05)$, and altruism $(\beta=-.17 ; \mathrm{p}<.05)$, accounting for $16.9 \%, 4.2 \%$, and $2.8 \%$ of the variance in burnout. These results indicated that higher level of burnout was a function of higher level of work-related problems/stressors, being younger, and 
lower level of self-compassion and altruism. Overall, the model explained about 56.5\% of the variance in compassion satisfaction $(R=.75)$.

Table 4. Results of Multiple Regression Analysis - Predictors of Burnout

\begin{tabular}{llllllll}
\hline Factor & $R$ & $R^{2}$ & $\beta$ & $t$ & $p$ & $F$ & $P$ \\
\hline Work-related problems/stressors & .57 & .33 & .50 & 8.18 & .000 & 63.74 & .000 \\
Self-compassion & .70 & .49 & -.35 & -5.41 & .000 & 64.06 & .000 \\
Age & .73 & .54 & -.19 & -2.92 & .004 & 50.23 & .000 \\
Altruism & .75 & .57 & -.17 & -2.87 & .005 & 41.82 & .000 \\
\hline
\end{tabular}

4.3 Sources, Predictors, and Management of Work-related Stress

In this study, the participants identified several issues and trends that occurred in their program. The majority witnessed the use of performance measures (72\%), increased use of technology $(71 \%)$, use of evidence-based practice models $(62 \%)$, and use of consultants in their programs $(46 \%)$. Some also reported that they experienced agency staff cut-backs $(23 \%)$, program cut backs/closures $(27 \%)$, program not adequately funded (38\%), and that the program focused on the "bottom line" that compromised service quality (33\%). These agency problems may place Asian-American social workers at higher risk of work-related stress.

A stepwise multiple regression analysis was conducted to estimate a model that would best predict the experience of stress perceived by these participants. Eight possible factors including age, gender, income, job tenure, work-related problems/stressors, self-compassion, altruism, and social work idealism were entered. The results revealed three factors as significant predictors $(F=36.94 ; p<.05)$. With a beta of $-.54(p<.05)$, self-compassion emerged as the strongest predictor, accounting for $39 \%$ of the variance in perceived stress (Table 5). The second strongest factor was work-related problems $(\beta=.23 ; \mathrm{p}<.05)$ followed by job tenure $(\beta=-.14 ; \mathrm{p}<.05)$ accounting for $5 \%$ and $1.8 \%$ of the variance in perceived stress. These results indicated that higher level of perceived stress was a function of lower level of self-compassion, higher level of work-related problems, and longer job tenure. Overall, the model explained almost $46 \%$ of the variance in perceived stress $(R=.68)$.

Table 5. Results of Multiple Regression Analysis - Predictors of Perceived Stress

\begin{tabular}{llllllll}
\hline Factor & $R$ & $R^{2}$ & $\beta$ & $t$ & $p$ & $F$ & $P$ \\
\hline Self-compassion & .62 & .39 & -.54 & -7.93 & .000 & 84.95 & .000 \\
Work-related problems/stressors & .66 & .44 & .23 & 3.45 & .001 & 51.82 & .000 \\
Job Tenure & .68 & .46 & -.14 & -2.11 & .037 & 36.94 & .000 \\
\hline
\end{tabular}

One hundred and sixty-five participants in this study shared the strategies that helped them in managing their work-related stress and regaining a sense of control over their situations. Notably, for Asian-American social workers in this sample, physical activity was the leading method of alleviating stress $(\mathrm{N}=104,63 \%)$, followed by body, mind, and spirit approach $(\mathrm{N}=94,57 \%)$, and gaining support through a professional or social support $(\mathrm{N}=87,53 \%)$. Some participants sought professional services such as therapy or counseling $(\mathrm{N}=45,27 \%)$. Very few participants used absenteeism $(\mathrm{N}=25,15 \%)$, drinking alcohol $(\mathrm{N}=41.24 \%)$, smoking cigarette $(\mathrm{N}=7,4 \%)$, and taking prescription drugs $(\mathrm{N}=12,7 \%)$ to cope with work-related stress.

\subsection{Factors Attributing to Job-related Health Problems}

A stepwise multiple regression analysis was conducted to estimate a model that would best predict the experience of job-related health problems among these participants. Eight possible factors including age, gender, income, job tenure, work-related problems/stressors, self-compassion, altruism, and social work idealism were entered. The results revealed four factors as significant predictors $(F=35.13 ; p<.05)$. With a beta of .55 ( $p<.05)$, work-related problems/stressors emerged as the strongest predictor, accounting for $42.2 \%$ of the variance in job-related health problems (Table 6). The second strongest factor was self-compassion, $(\beta=-.21 ; p<.05)$ followed by gender $(\beta=.14$; $\mathrm{p}<.05)$, and job tenure $(\beta=-.13 ; \mathrm{p}<.05)$, accounting for $6 \%, 2.6 \%$, and $1.5 \%$ of the variance in job-related health problems. These results indicated that higher level of job-related health problems was a function of higher level of work-related problems/stressors, lower level of self-compassion, being female, and shorter job tenure. Overall, the model explained almost $52.3 \%$ of the variance in job-related health problems $(R=.72)$. 
Table 6. Results of Multiple Regression Analysis - Predictors of Job-Related Health Problems

\begin{tabular}{llllllll}
\hline Factor & $R$ & $R^{2}$ & $\beta$ & $T$ & $P$ & $F$ & $P$ \\
\hline Work-related problems/stressors & .65 & .42 & .55 & 8.62 & .000 & 95.47 & .000 \\
Self-compassion & .69 & .48 & -.21 & -3.16 & .002 & 60.41 & .000 \\
Gender & .71 & .51 & .14 & 2.27 & .025 & 44.41 & .000 \\
Job tenure & .72 & .52 & -.13 & -2.02 & .045 & 35.13 & .000 \\
\hline
\end{tabular}

5. Discussion

\subsection{Major Findings}

Compassion satisfaction is an important concept capturing the pleasure and satisfaction derived from helping others and has been shown to be a protective factor for social workers to cope with work-related stress in direct practice (Stamm, 2002). Compassion fatigue, on the other, was found to associate with a sense of helplessness, confusion, and social isolation (Figley, 2002). Compassion fatigue was related to psychological distress among social workers (Adams et al., 2006). The finding of this study of Asian-American social workers was consistent with the literature and showed that higher level of burnout was associated with higher level of secondary trauma and lower level of compassion satisfaction. However, there was no relationship between compassion satisfaction and secondary trauma.

Personal distress is an important construct capturing "self-oriented feelings of personal anxiety and unease in tense interpersonal settings" (Davis, 1983, p, 114). Thomas (2013) studied personal distress experienced by 171 licensed clinical social workers and found that higher personal distress was associated with higher compassion fatigue and burnout and lower compassion satisfaction. This study examined two similar constructs - perceived stress and work-related problems/stressors experienced by 208 Asian-American social workers and found significant relationships between both constructs and major variables of professional quality of life - compassion satisfaction, secondary trauma, and burnout. The findings showed that higher perceived stress was associated with higher secondary trauma, burnout, job-related health problems, and lower compassion satisfaction. Regression analyses found that work-related problems/stressors emerged as a very strong predictor of burnout (accounting for $32.6 \%$ of the variance) and job-related health problems (accounting for $42.2 \%$ of the variance). Work-related problems/stressors was also a factor predicting secondary trauma (accounting for $5.6 \%$ of the variance) and compassion satisfaction (accounting for $2.9 \%$ of variance).

Self-compassion was defined as "being open to and moved by one's own suffering, experiencing feelings of caring and kindness toward oneself, taking an understanding, nonjudgmental attitude toward one's inadequacies and failures, and recognizing that one's own experience is part of the common human experience" (Neff, 2003, p. 224). This study found that self-compassion was an important factor influencing the professional quality of life among Asian-American social workers. The results showed that higher self-compassion was associated with higher compassion satisfaction and lower secondary trauma and burnout. Self-compassion was also found to be a very strong predictor of perceived stress (accounting for $39 \%$ of the variance) and a factor predicting job-related health problems, accounting for $6 \%$ of the variance.

\subsection{Study Limitations}

There are limitations to this study. First, study participants were diverse in age, ethnicity, immigration status, income level, religion, and what regions/states they lived. However, the study was subject to sampling bias inherent to convenience and snowball sampling. Therefore, this sample may not have been representative of Asian-American social worker populations at large, and results were limited in generalizability. Second, analyzes of results in cross-sectional survey design employed in this study cannot assert causality. Third, all the analyses rely on self-report data based on online surveys and may result in recall bias and observation bias; the extent of these biases may have varied in accordance with how long they have worked as a social worker and how they perceive their work environment and their career. These biases were circumvented by encouraging the participants to answer each question honestly and that their responses would be completely anonymous.

\subsection{Implications and Conclusion}

There is a paucity of literature on Asian-American social workers' career experiences and work-related stress. This study contributed to more knowledge and understanding of factors that might associate with specific career experiences and work-related stress among this understudied population. Greater understanding of the work-related stress and career experience among them is much needed to further our knowledge on the possible link between 
work-related stressors, career experience, self-compassion, and their psychological and physical well-being. The current study has several implications for professional development and education for Asian-American social workers.

Work-related stress is common in today's workforce, including persons practicing social work. Given the profession's client-centered nature and complexity of client situations and needs, stress is a major concern among these Asian-American social workers who provide direct services. These social workers shared that they experienced numerous work-related challenges and stressors including heavy workload, being unable to balance professional and personal life, difficult/challenging clients, receiving few resources to adequately accomplish work tasks, inadequate compensation, and limited opportunities for career advancement. They also faced critical challenges and issues in their agency such as increased use of performance measures, technology, and evidence-based practice models, cutbacks in staff, and programs not adequately funded and focused on the bottom line that compromised service quality. It was not surprising that they experienced higher level of work-related stress. Under less-than-optimal work conditions (limited resources and getting minimal support from co-workers and/or supervisors), they were often "pushed to the limit" when trying to complete their work. Over time, work-related stress could result in burnout, work place injury, impaired performance, impaired cognitive functioning, decreased concentration, and poor health and mental health (Arrington, 2008; Kwong, 2016). Additionally, these issues might also cause these professionals to consider a career change, resulting in more and more challenges in retention of Asian-American social work workforce and causing more service gaps for Asian-American populations due to inadequate number of Asian-American social workers in the first place.

Reestablishing a sense of control, mastery, and competence in one's work situation may seem a daunting task. However, with stress management strategies like physical activity, body, mind, and spirit approach, and gaining support through professional and social networks, used by these social workers, alleviating work- related stress and promoting psychological and physical well-beings can be an attainable goal. For them, stress management strategies became very essential to help sustain effective careers in highly stressful and demanding work settings. The results of this study focused on the experience of work-related stressors and perceived stress and placed emphasis on what these helping professionals could in fact, be able to control to better manage their own reaction to stressful work experiences. A particular important finding in this study was the role of self-compassion in the professional quality of life, perceived stress, and experience of job-related health problems among these Asian-American social workers. This finding was consistent with the literature that self-compassion had a significant negative correlation with anxiety and depression, and a significant positive correlation with life situation (Neff, 2003). This suggests that self-compassion can be an important adaptive mechanism that may enhance positive coping and psychological and physical well-beings of these professionals. Enhancing level of self-compassion as an area of professional education and support should be explored in future research.

In summary, social workers can learn to respond to work-related stressors and problems in healthy ways and obtain personal and professional support to meet their social and emotional needs. Within the social work profession, it is important to emphasize the needs for self-awareness and self-compassion and creating an expectation for ongoing self-care that is part of the professional identity. To enhance retention of Asian-American social work professionals, professional development and education that provide structured opportunities for them to be reflective on their personal and professional experiences is very much needed. Despite the opportunities that social work offers, participants in this study expressed much concerns about their career in social work. This suggests that enhancing recruitment and retention of Asian-American social workers in the long term may require changes not only in the professional education and development but also in the conditions of employment.

\section{Acknowledgements}

I whole heartedly thank all the respondents for their eager participation in this comprehensive survey and their willingness and openness in sharing their career decisions and professional experiences, as well as their social work career. I also want to thank many Asian-American based service organizations and networks, schools and institutions, and social work student groups who actively shared the study with their members and colleagues. The study was supported by the Touro College Graduate School of Social Work.

\section{References}

Adams, R. E., Boscarino, J. A., \& Figley, C. R. (2006). Compassion fatigue and psychological distress among social workers: A validation study. American Journal of Orthopsychiatry, 76(1) 102-108. http://dx.doi.org/10.1037/0002-9432.76.1.103 
Arrington, P. (2008). Stress at work: How do social workers cope? NASW Membership Workforce Study. Washington, DC: National Association of Social Workers.

Badger, K., Royse, D., \& Craig, C. (2008). Hospital social workers and indirect trauma exposure: An exploratory study of contributing factors. Health and Social Work, 33(1), 63-71. http://dx.doi.org/10.1093/hsw/33.1.63

Baker, E. (2003). Caring for ourselves as psychologists. Retrieved from http://www.e-psychologist.org/index.iml?mdl=exam/show_article.mdl\&Material_ID=1

Barnett, J. E., Baker, E. K., Elman, N. S., \& Schoener, G. R. (2007). In the pursuit of wellness: The self-care imperative. Professional Psychology: Research and Practice, 38(6), 603-612. http://dx.doi.org/10.1037/0735-7028.38.6.603

Bongar, B., Stolberg, R. (2009). Risk management with the suicidal patient. Washington, DC: National Register of Health Service Psychologists; 2009.

Bride, B, E. (2007). Prevalence of secondary traumatic stress among social workers. Social Work, 52(1), 63-70. http://dx.doi.org/10.1093/sw/52.1.63

Cohen, S., Kamarck, T., and Mermelstein, R. (1983). A global measure of perceived stress. Journal of Health and Social Behavior, 24, 386-396. https://doi.org/10.2307/2136404

Collins, S, \& Long, A. (2003). Working with psychological effects of trauma: Consequences for mental health-care workers: A literature review. Journal of Psychiatric and Mental Health Nursing, 10, 417-424. https://doi.org/10.1046/j.1365-2850.2003.00620.x

Council on Social Work Education (2017). 2016 Statistics on social work education in the United States. Retrieved from https://www.cswe.org/CMSPages/GetFile.aspx?guid=6e8bc9e7-ebd6-4288-bc7a-d2d427d68480

Cox, K., \& Steiner, S. (2013). Self-care in social work: A Guide for practitioners, supervisors, and administrators. Washington, DC: NASW Press.

Coyle, D., Edwards. D., Hannigan, B., Fothergill, A., \& Burnard, P. (2005). A systematic review of stress among mental health social workers. International Social Work, 48(2), 201-211. https://doi.org/10.1177/0020872805050492

Csikai, E., \& Rozensky, C. (1997). 'Social work idealism' and students' perceived reasons for entering social work. Journal of Social Work Education, 33(3), 529-538. https://doi.org/10.1080/10437797.1997.10778891

Daniel, C. (2011). The path to social work: Contextual determinants of career choice among racial/ethnic minority students. Social Work Education, 30(8), 895-910. https://doi.org/10.1080/02615479.2010.520121

Davis, M. H. (1983). Measuring individual differences in empathy: Evidence for a multi-dimensional approach. Journal of Personality and Social Psychology, 44(1), 113-126. https://doi.org/10.1037/0022-3514.44.1.113

Dziegielewski, S. F., Turnage, B., \& Roest-Marti, S. (2004). Addressing stress with social work students: a controlled evaluation. Journal of Social Work Education, 40(1), 105-119. https://doi.org/10.1080/10437797.2004.10778482

Fahy, A. (2007). The unbearable fatigue of compassion: Notes from a substance abuse counselor who dreams of working at Starbucks. Clinical Social Work Journal, 35(3), 199-205. http://dx.doi.org/10.1007/s10615-007-0094-4

Figley C. R. (1999). Compassion fatigue: toward a new understanding of the costs of caring. In: Stamm BH, ed. Secondary traumatic stress: Self-care issues for clinicians, researchers, and educators. $2 \mathrm{nd}$ ed. Lutherville, MD: Sidran Press; 3-28.

Figley, C. R. (2002). Compassion fatigue: Psychotherapists' chronic lack of self-care. Journal of Clinical Psychology, 58(11), 1433-1441. http://dx.doi.org/10.1002/jclp.10090

Gately, L. A, \& Stabb, S. D. (2005). Psychology students' training in the management of potentially violent clients. Professional Psychology: Research and Practice, 36(6), 681-687. https://doi.org/10.1037/0735-7028.36.6.681

Hwang, Hwang, M. J. (2007) Asian social workers' perceptions of glass ceiling, organizational fairness and career prospects. Journal of Social Service Research, 33(4), 13-24. https://doi.org/10.1300/J079v33n04_02

Kwong, K. (2016). Understanding work-related stress and practice of professional self-care - An Innovative pedagogical approach. International Journal of Higher Education, 5(4), 41-51. 
http://dx.doi.org/10.5430/ijhe.v5n4p41

Lee, S. M. (2009). Asian American social workers: Exploring relationships among factors influencing career choices. Dissertation Abstracts International: Section B: Sciences and Engineering, 70(1-A), 351.

Moriarty, J. \& Murray, J. (2007). Who wants to be a social worker? Using routine published data to identify trends in the numbers of people applying for and completing social work programs in England. British Journal of Social Work, 37(4), 715-733. https://doi.org/10.1093/bjsw/bch325

Naturale, A. (2007). Secondary traumatic stress in social workers responding to disasters: Reports from the field. Clinical Social Work Journal, 35(3), 173-181. http://dx.doi.org/10.1007/s10615-007-0089-1

Neff, K. D. (2003). Development and validation of a scale to measure self-compassion. Self and Identity, 2, $223-250$. https://doi.org/10.1080/15298860309027

Newell, J. M., \& MacNeil, G. (2010). Professional burnout, secondary traumatic stress, and compassion fatigue: A review of theoretical terms, risk factors, and preventive methods for clinicians. Best Practices in Mental Health, $6(2), 57-68$.

Pew Research Center (2017). Key facts about Asian Americans, a diverse and growing population. Retrieved from http://www.pewresearch.org/fact-tank/2017/09/08/key-facts-about-asian-americans/

Pryce, J. G., Shackelford, K. K., \& Pryce, D. H. (2007). Secondary traumatic stress and the child welfare professional. Chicago: Lyceum.

Schaufeli, W. B., Leiter, M. P., \& Maslach, D. (2009). Burnout: 35 years of research and practice. Career Development International, 14(3), 204-220. http://dx.doi.org/10.1108/13620430910966406

Shoji, K., Bock, J., Cieslak, R., Zukowska, K., Luszczynska, A., Benight, C. C. (2014). Cultivating secondary traumatic growth among healthcare workers: The role of social support and self-efficacy. Journal of Clinical Psychology, 70(9), 831-846. http://dx.doi.org/10.1002/jclp.22070

Smullens, S. (2012). What I wish I had known: burnout and self-care in our social work profession. New Social Worker, 19(4), 6-9.

Stamm, B. (2002). Measuring compassion fatigue in psychotherapists. In: Figley CR, ed. Treating compassion fatigue. New York, NY: Brunner/Rutledge.

Stamm, B. (2009-2012). Professional quality of life: Compassion satisfaction and fatigue version 5 (ProQOL). Retrieved from http://proqol.org/

Thomas, J. (2013). Association of personal distress with burnout, compassion fatigue, and compassion satisfaction among clinical social workers. Journal of Social Service Research, 39, 365-379. https://doi.org/10.1080/01488376.2013.771596

Ting, L., Saunders, S., Jacobson, J., \& Power J. (2006). Dealing with the aftermath: A qualitative analysis of mental health social workers' reactions after a client suicide. Social Work, 51(4), 329-341. http://dx.doi.org/10.1093/sw/51.4.329

United States Census Bureau (2015). ACS demographic and housing estimates: 2015 American community survey 1-year estimates. Retrieved from https://factfinder.census.gov/faces/tableservices/jsf/pages/productview.xhtml?src=bkmk

Weitcamp, K., Daniels, J. K., \& Klasen, F. (2014). Psychometric properties of the questionnaire for secondary traumatization. European Journal of Pychotraumatology, 5, 1-12. http://dx.doi.org/10.3402/ejpt.v5.21875

Wilson, G. \& McCrystal, P. (2007). Motivations and career aspirations of MSW students in Northern Ireland. Social Work Education, 26(1), 35-52. https://doi.org/10.1080/02615470601036534 